\title{
An update on endometriosis associated subfertility: what does the most recent evidence say?
}

\author{
Karim Abdallah* \\ Department of Obstetrics and Gynecology, Sheffield Teaching Hospitals, Sheffield, United Kingdom
}

Received: 03 October 2018

Accepted: 27 October 2018

\section{*Correspondence:}

Dr. Karim Abdallah,

E-mail: karimhassanfathy@yahoo.com

Copyright: $\odot$ the author(s), publisher and licensee Medip Academy. This is an open-access article distributed under the terms of the Creative Commons Attribution Non-Commercial License, which permits unrestricted non-commercial use, distribution, and reproduction in any medium, provided the original work is properly cited.

\begin{abstract}
Endometriosis is a chronic debilitating disease that affects $10 \%$ of women in the reproductive age. Women with endometriosis present with pain, subfertility or both. The prevalence of endometriosis in women with subfertility is estimated to be within the range of $40 \%-50 \%$. This is a review of the evidence published in the literature. The review was conducted via searching the databases of the Cochrane reviews, European Society of Human Reproduction and Embryology (ESHRE), American Society of Obstetrics and Gynaecology (ACOG), National Institute for Clinical Excellence (NICE) and British Medical Journal (BMJ) best practice articles. Management of women with endometriosis and subfertility has been extensively assessed in the literature. Medical management, surgical approaches and a combination of both improve the spontaneous pregnancy rates for this cohort of patients.
\end{abstract}

Keywords: Endometriosis, Laparoscopy, Subfertility

\section{INTRODUCTION}

\section{Definition}

Endometriosis is characterised by the presence of endometrial tissue in sites other than the uterine cavity. ${ }^{1}$ The presence of active endometrial tissue outside the uterine cavity induces an inflammatory reaction of variable degrees. The result of the inflammatory reaction is scar tissue formation. Subfertility associated with endometriosis is thought to be the result of scarring and/or over-production of prostaglandins which in turn impairs fertilization and implantation. ${ }^{2}$ Endometriosis is generally believed to be an estrogen-dependent disorder. ${ }^{1}$

\section{Magnitude of the problem}

Women with endometriosis most commonly present with pain and/or subfertility. The prevalence is very variable.
The general estimates of prevalence of endometriosis among women of the reproductive age varies from $2 \%$ to $10 \% .^{3}$ For women with subfertility the prevalence is estimated to be in the range of $40 \%$ to $50 \%$.,

The numbers are expected to be under-estimates since a great proportion of the diagnosis depends on surgical identification of the disease and histopathological confirmation.

The ENDO Study Working Group have concluded that endometriosis is probably more prevalent than previously estimated. This conclusion was derived from combining operative findings and MRI studies. ${ }^{6}$

This is a review of the evidence published in the literature. The review was conducted via searching the databases of the Cochrane reviews, ESHRE, ACOG, NICE and BMJ best practice articles. 


\section{DIAGNOSIS}

\section{Symptoms}

Endometriosis commonly presents with pain and/or subfertility. The presence of risk factors such as women of reproductive age, family history and nulliparity is a clue to diagnosis. Despite being most prevalent in women of the reproductive age group, endometriosis has been diagnosed in a wider age spectrum. ${ }^{7,8}$ Endometriosis is more likely to be diagnosed in nulliparous than multiparous women. ${ }^{9}$ There is weak association with white ethnicity, low BMI and late first sexual intercourse. $^{10}$ In terms of pain, endometriosis most commonly presents with dysmenorrhea, dyspareunia and chronic or cyclic pelvic pain. $40 \%$ of women with unexplained subfertility are diagnosed with endometriosis. Due to the wide range of presentation, studies have reported an 8-year average delay in diagnosis of endometriosis in the UK. ${ }^{11}$

\section{Clinical examination}

Generalized pelvic tenderness, pelvic masses and limited pelvic organs mobility, nodularity od the rectovaginal septum and 'guitar string' consistency of the uterosacral ligaments are all findings suggestive of pelvic endometriosis. The evidence on the value of clinical examination in the diagnosis of endometriosis is weak and mainly based on cohort studies. ${ }^{3}$ The ESHRE Guideline Development Group (GDG) recommends that clinicians may consider the diagnosis of endometriosis in women suspected of the disease even if the clinical examination was normal (Evidence level C).

\section{Investigations}

NICE has published the recommended workup for diagnosis of subfertility. This article focuses on the diagnosis of endometriosis in women presenting with subfertility. Transvaginal USS can detect ovarian endometriomas with $93 \%$ sensitivity and $96 \%$ specificity and Uterosacral ligament involvement with $53 \%$ sensitivity and $93 \%$ specificity. ${ }^{12,13}$ MRI to diagnose or exclude pelvic endometriosis was evaluated in a case series of 44 women with suspected endometriosis. Compared to the gold standard for diagnosis, diagnostic laparoscopy and biopsy, the positive LR was 2.76 and the negative LR was $0.41 .^{14}$ These LR were too low to recommend MRI as a useful test to diagnose or exclude endometriosis. One study reported the value of MRI to detect the severity of the disease in women with an established diagnosis of endometriosis. ${ }^{15}$ The Positive LR ranged from 12.0 to 41.7 and negative LR ranging from 0.1 to 0.2 , these LR conclude that MRI is a good test to predict if the bowel wall has been infiltrated by endometriosis and is a moderate test to exclude rectal infiltration.
The gold standard for diagnosis is identification of endometriosis on visual inspection during a diagnostic laparoscopy with histological confirmation. A laparoscopy where endometriosis was not detected on visual inspection is adequate to reassure a woman about the unlikelihood of the disease. However, a positive identification of the disease by visual inspection (without histological confirmation) is of limited value for diagnosis. ${ }^{3}$

The value of non-invasive testing has been explored on several studies. CA-125 was studied in a meta-analysis performed by Mol and co-workers. ${ }^{16}$ The review concluded that there is limited potential for CA-125 to diagnose endometriosis. No current biological marker is able to diagnose endometriosis.

Clinicians should assess ureter, bladder, and bowel involvement by additional imaging if there is a suspicion based on history or physical examination of deep endometriosis, in preparation for further management. ${ }^{3}$ These can include MRI examination, transvaginal Ultrasound scans (USS), transrectal USS and Barium enema.

\section{GRADES AND CLASSIFICATION OF ENDOMETRIOSIS}

The American Society for Reproductive Medicine (ACRM) has published their revised scoring system of endometriosis based on visual inspection during laparoscopy. The classification divides the disease into 4 stages

\section{Stage I (minimal)}

- Total score 1 to 5 .

- $\quad$ Small, superficial peritoneal or adnexal implants $(<1$ to $3 \mathrm{~cm}$ ); filmy adhesions.

Stage II (mild)

- $\quad$ Total score 6 to 15 .

- $\quad$ Larger lesions (>3 cm), some deeply infiltrating.

Stage III (moderate)

- Total score 16 to 40 .

- Larger lesions, more of which are infiltrative, partial cul-de-sac obliteration; dense adhesions involving adnexa.

Stage IV (severe)

- Total score $>40$.

- Deep ovarian lesions (endometrioma) with dense adnexal adhesions; cul-de-sac obliteration. 
Despite being originally intended to predict fertility outcomes, this classification method has been criticised for its poor predictive value. ${ }^{2}$

\section{TREATMENT}

It has been established that the most common approaches to manage subfertility associated with endometriosis are hormonal treatment, surgical management or both. Hughes et al have evaluated the role of ovarian suppression in the treatment of endometriosis in a systematic Cochrane review. ${ }^{17}$ Despite a high-quality systematic review, the emerging evidence was extremely limited by the quality of the studies included in the review. The ESHRE guideline development group (GDG) have therefore recommended that clinicians should not prescribe ovarian suppression treatment for infertile women with endometriosis. ${ }^{3}$ Laparoscopic treatment of endometriosis by ablation and/or excision and adhesiolysis. Following surgery, cumulative spontaneous pregnancy rate within 3 years has gone up to $46 \%-77 \%$ for patients with moderate endometriosis and up to $44 \%-74 \%$ for patients with severe endometriosis. ${ }^{18,19}$ NICE recommends that clinicians should aim to excise endometriomas rather than drainage and ablation. ${ }^{20}$ Excision of the cyst wall reduces recurrence and improves the spontaneous pregnancy rates compared to drainage and ablation. There is a $2.4 \%$ risk of ovarian failure following excision of endometrioma. ${ }^{21}$ No evidence was found to support the use of pre- and/or post-operative hormonal treatment to improve fertility outcomes in women with endometriosis associated subfertility.

The evidence was extracted from the systematic Cochrane review conducted by Furness et al. ${ }^{22}$ Intrauterine insemination (IUI) is more effective in improving the live pregnancy rates in patients with minimal or mild endometriosis. The effectiveness of IUI can be further improved by controlled ovarian stimulation. $^{3}$ For women with moderate and severe endometriosis, IVF seems to be a more reasonable alternative. There is no evidence to suggest that hormonal treatment prior to IVF in those patients increases the risk of recurrence of the disease. ${ }^{23}$ Despite the widespread use of alternative and complimentary medicine among patients with endometriosis, there are no available highquality studies to provide evidence strong enough to advise with or against the use of such remedies.

\section{PROGNOSIS}

Endometriosis is a disease characterized by being recurrent. It is very difficult to establish a prognosis in terms of subfertility. Subfertility is also affected by other contributing factors such as age, anovulation and male factor. I 2016, Saraswat et al published the outcomes of their study involving 15,000 women and followed up for 30 years. The study concluded that there is a statistically significant relation between a positive history and first and third trimester obstetrical complications. ${ }^{24}$

Funding: No funding sources

Conflict of interest: None declared

Ethical approval: Not required

\section{REFERENCES}

1. Brown J, Farquhar C. Endometriosis: an overview of Cochrane Reviews. Cochrane Database of Systematic Reviews. 2014;(3):CD009590.

2. BMJ best practice article on Endometriosis. 2018. Available at: https://www.bmj.com/content/323/7304/93.

3. Management of women with endometriosis. ESHRE Endometriosis Guideline Development Group. September 2013. Available at: https://www.eshre.eu/ /media/sitecorefiles/Guidelines/Endometriosis/ESHRE-guidelineon-endometriosis-2013.pdf.

4. Ozkan S, Murk W, Arici A. Endometriosis and Infertility. Epidemiology and evidence based treatments. Annals New York Academy Sci. 2008;1127:92-100.

5. Meuleman C, Vandenabeele B, Fieuws S, Spiessens C, Timmerman D, D'Hooghe T. High prevalence of endometriosis in infertile women with normal ovulation and normospermic partners. Fertil Steril. 2009;92:68-74.

6. Peterson CM, Johnstone EB, Hammoud AO, Stanford JB, Varner MW, Kennedy A, et al. Risk factors associated with endometriosis: importance of study population for characterizing disease in the ENDO Study. Am J Obstet Gynecol. 2013;208(6):451-e1.

7. Marsh EE, Laufer MR. Endometriosis in premenarcheal girls who do not have an associated obstructive anomaly. Fertil Steril. 2005;83(3):75860.

8. Al Kadri H, Hassan S, Al-Fozan HM, Hajeer A. Hormone therapy for endometriosis and surgical menopause. Cochrane Database Syst Rev. 2009;(1):CD005997.

9. Leyland N, Casper R, Laberge P, Singh SS, Allen L, Arendas K, et al. Endometriosis: diagnosis and management. J Endometriosis. 2010;2(3):107-34.

10. Missmer SA, Hankinson SE, Spiegelman D, Barbieri RL, Malspeis S, Willett WC, et al. Reproductive history and endometriosis among premenopausal women. Obstet Gynecol. 2004;104(5 Pt 1):965-74.

11. Ballard K, Lowton K, Wright J. What's the delay? A qualitative study of women's experiences of reaching a diagnosis of endometriosis. Fertil Steril. 2006;86:1296-301.

12. Nisenblat V, Bossuyt PM, Farquhar C, Johnson N, Hull ML. Imaging modalities for the non-invasive diagnosis of endometriosis. Cochrane Database Syst Rev. 2016;(2):CD009591. 
13. Guerriero S, Ajossa S, Minguez JA, Jurado M, Mais $\mathrm{V}$, Melis GB, et al. Accuracy of transvaginal ultrasound for diagnosis of deep endometriosis in uterosacral ligaments, rectovaginal septum, vagina and bladder: systematic review and meta-analysis. Ultrasound Obstet Gynecol. 2015;46(5):534-45.

14. Stratton P, Winkel C, Premkumar A, Chow C, Wilson J, Hearns-Stokes R, et al. Diagnostic accuracy of laparoscopy, magnetic resonance imaging, and histopathologic examination for the detection of endometriosis. Fertil Steril. 2003;79:1078-85.

15. Chapron C, Vieira M, Chopin N, Balleyguier C, Barakat H, Dumontier I, et al. Accuracy of rectal endoscopic ultrasonography and magnetic resonance imaging in the diagnosis of rectal involvement for patients presenting with deeply infiltrating endometriosis. Ultrasound Obstet Gynecol. 2004;24(2):175-9.

16. Mol BW, Bayram N, Lijmer JG, Wiegerinck MA, Bongers MY, van der Veen F, et al. The performance of CA-125 measurement in the detection of endometriosis: a meta-analysis. Fertil Steril. 1998;70:1101-8.

17. Hughes E, Brown J, Collins JJ, Farquhar C, Fedorkow DM, Vandekerckhove P. Ovulation suppression for endometriosis for women with subfertility. Cochrane Database Syst Rev 2007:CD000155.

18. Nezhat C, Crowgey S, Nezhat F. Videolaseroscopy for the treatment of endometriosis associated with infertility. Fertil Steril. 1989; 51:237-40.

19. Vercellini P, Fedele L, Aimi G, De Giorgi O, Consonni D, Crosignani PG. Reproductive performance, pain recurrence and disease relapse after conservative surgical treatment for endometriosis: the predictive value of the current classification system. Hum Reprod. 2006;21:267985.

20. Endometriosis: diagnosis and management. National Institute for Clinical Excellence (NICE) guideline. 2017. Available at: nice.org.uk/guidance/ng73.

21. Busacca M, Chiaffarino F, Candiani M, Vignali M, Bertulessi C, Oggioni G, et al. Determinants of longterm clinically detected recurrence rates of deep, ovarian, and pelvic endometriosis. Am J Obstet Gynecol. 2006;195(2):426-32.

22. Furness S, Yap C, Farquhar C, Cheong YC. Pre and post-operative medical therapy for endometriosis surgery. Cochrane Database Syst Rev. 2004:CD003678.

23. Benaglia L, Somigliana E, Santi G, Scarduelli C, Ragni G, Fedele L. IVF and endometriosis-related symptom progression: insights from a prospective study. Hum Reprod. 2011;26:2368-72.

24. Saraswat L, Ayansina DT, Cooper KG, Bhattacharya S, Miligkos D, Horne AW. Pregnancy outcomes in women with endometriosis: a national record linkage study. BJOG. 2017;124(3):444-52.

Cite this article as: Abdallah K. An update on endometriosis associated subfertility: what does the most recent evidence say?. Int J Reprod Contracept Obstet Gynecol 2018;7:5226-9. 